\title{
Research Progress of Related Laboratory Testing Indexes before and after Mother-Infant Blocking in HIV/AIDS Pregnant Women
}

\author{
Guosheng Su${ }^{* \#, ~ L i h u a ~ Q i n ~}{ }^{2 * \#, ~ L i d a ~} M^{3}$ \\ ${ }^{1}$ Department of Clinical laboratory, Guigang Hospital of Integrated Traditional Chinese and Western Medicine, Guigang Red \\ Cross Hospital, Guiyang, China \\ ${ }^{2}$ Department of Osteoarthritis, Guigang Hospital of Integrated Traditional Chinese and Western Medicine, Guigang Red Cross \\ Hospital, Guiyang, China \\ ${ }^{3}$ Department of Clinical laboratory, The Fourth People's Hospital Nanning Guangxi, Guangxi Medical University Affiliated to \\ Infectious Diseases Hospital of Nanning, Guangxi AIDS Clinical Treatment Center (Nanning), Nanning, China \\ Email: \#563449581@qq.com, \#787209349@qq.com, 1773398578@qq.com
}

How to cite this paper: Su, G.S., Qin, L.H. and Mo, L.D. (2020) Research Progress of Related Laboratory Testing Indexes before and after Mother-Infant Blocking in HIV/AIDS Pregnant Women. World Journal of AIDS, 10, 149-157. https://doi.org/10.4236/wja.2020.102013

Received: June 4, 2020

Accepted: June 27, 2020

Published: June 30, 2020

Copyright $\odot 2020$ by author(s) and Scientific Research Publishing Inc. This work is licensed under the Creative Commons Attribution International License (CC BY 4.0).

http://creativecommons.org/licenses/by/4.0/

\begin{abstract}
More than $90 \%$ of HIV-positive children come from mother-to-child transmission, so mother-to-child interdiction is the main measure to prevent AIDS in children. Relevant data show that the incidence of mother-to-child transmission of HIV usually fluctuates between $15 \%$ and $50 \%$ without intervention. Standardized and effective comprehensive intervention can reduce the transmission rate of mother to child to less than $1 \%$. At present, it is believed that mother-to-child transmission of AIDS can be blocked by comprehensive intervention, and its mechanism has been clearly studied. Combined with highly effective antiviral treatment, safe labor and artificial feeding, the mother to child transmission rate can be reduced to less than $1 \%$. However, due to the effect of drugs on mother-to-child transmission of AIDS may lead to some changes in the main biochemical indicators of mother-to-child, there is no systematic analysis of the viral load, T lymphocyte subsets and major biochemical indicators of HIV/AIDS pregnant women before and after maternal-to-child transmission. In this study, the viral load, T lymphocyte subsets and major biochemical indicators of HIV/AIDS pregnant women before and after maternal-infant blockade were dynamically analyzed. It is hoped that this study will help to observe the basic physical fitness and disease development of pregnant women with HIV/AIDS during pregnancy, to provide a strong basis for the treatment and evaluation of maternal-infant blockade of HIV/AIDS pregnant women, and to establish a complete set of laboratory indicators to understand the body status of pregnant women at all stages to
\end{abstract}

${ }^{\star}$ Co-first authors.

\#Corresponding authors. 
minimize the probability of fetal transmission, which will make good economic and social benefits.

\section{Keywords}

AIDS, Pregnant Women, Prevention of Mother to Child Transmission, Viral Load, T Lymphocyte, Biochemical Index

\section{Introduction}

Acquired immunodeficiency syndrome (AIDS) is a disease caused by human immunodeficiency virus infection that causes cellular immune deficiency. By 2016, one million people worldwide died of AIDS, with an estimated 36.7 million carrier of the AIDS, including 34.5 million adults, 2.1 million children and 17.8 million women aged 15 and over [1] [2]. According to the figures published by the Center for Disease Control and Prevention of China [3], by December 31, 2017, 758,600 HIV/AIDS carrier or HIV/AIDS patients were reported nationwide, with 239,300 deaths and 998,100 reported deaths over the years. The number of surviving HIV virus carriers was 4,374,000, and AIDS patients were 3,212,000. In 2017, new HIV/AIDS cases of 1,345,000 were found, among which 95,500 cases were HIV carrier, and 39,900 cases were AIDS patients, while 307 thousand patients were killed. Among the new HIV/AIDS cases, heterosexual transmission accounted for $69.16 \%$, homosexual transmission accounted for $25.5 \%$, and sexual transmission reached $95.1 \%$. What's more, injection drug transmission was $3.2 \%$, and mother-to-child transmission accounted for $0.4 \%$. Guangxi was the high incidence area of AIDS in China, with the infection rate ranking third only after Yunnan Province and Xinjiang Uygur Autonomous Region. As of December 31, 2017, 79,810 survivors and patients with AIDS were reported in Guangxi, accounting for $10.52 \%$ of the total reported survival in China. Among these, 3660 cases (45.18\%) were HIV/AIDS carrier, 43,750 cases (54.82\%) were HIV/AIDS patients, and 44,472 cases (18.58\%) were reported as deaths. Over the past years, the number of 124,282 cases of deaths has been reported. The situation is still grim [3] [4] [5] [6]. In recent years, good results have been achieved in mother-to-child interdiction, but mother-to-child transmission still exists, and the interdiction of mother-to-child transmission among pregnant women with HIV/AIDS cannot be relaxed [4] [5] [6]. Therefore, the research group designs relevant topics according to the actual situation, and makes a literature review as follows.

\section{Pattern of HIV/AIDS Maternal-Neonatal Transmission}

There are three main ways of mother-to-child transmission of HIV, namely intrauterine infection, intrapartum infection during childbirth, and postpartum 
breast infection. According to the mode of mother-to-child transmission, the measures to prevent mother-to-child transmission of HIV are voluntary counseling and testing of pregnant women, to recognize HIV infected people timely. And viral drugs can be used to intervene HIV in positive pregnant women. Moreover, cesarean section, artificial feeding and other measures can put into use to effectively reduce the risk of mother-to-child transmission of HIV. It is not difficult to know that mother to child transmission is one of the three ways to spread AIDS [7]-[12]. More than 90\% of HIV-positive children occur through mother-to-child transmission. Accordingly mother-to-child interdiction is the main measure to prevent AIDS in children. Studies have shown that without any intervention, the incidence of mother-to-child transmission of AIDS is 15\% to $50 \%$. By standardized and effective comprehensive intervention, the incidence of mother to child transmission decreased to less than $1 \%$. At present, it is believed that prevention of mother-to-child transmission of HIV can effectively prevent mother-to-child transmission, and the study of its blocking mechanism has also been made clear. Studies have also shown that combination of highly active antiretroviral therapy, obstructive safe delivery and postnatal artificial feeding can reduce the incidence of mother-to-child transmission to less than 1\% [12] [13] [14] [15]. Therefore, it is entirely possible for pregnant women with HIV infection to have babies without HIV infection. At present, in most parts of China, maternal-infant interdiction work has been carried out for HIV-positive pregnant women, and some encouraging results have achieved. However, due to various objective conditions, the work of mother-to-child interdiction of HIVpositive pregnant women is still difficult to carry out. It is gratifying that the Guangxi AIDS Clinical Treatment Center (Nanning) is at the forefront of the country in the work of mother-to-child interdiction of HIV-positive pregnant women. In Guangxi, pregnant women account for a certain proportion of people infected with HIV/AIDS. As pregnant women infected with HIV/AIDS, in a sense, they have the right to give birth to the next generation, and they also have the obligation to make this society harmonious, that is, to give birth to a healthy next generation. How to make rights and obligations do not conflict, which requires AIDS prevention workers pay more attention to the prevention work. In a word, the main responsibility for all kinds of medical workers at all levels is to conduct AIDS propaganda and carried on education. As the medical staff of Guangxi AIDS clinical treatment center, they feel that there is a long way to go, especially in how to stop the mother-to-child transmission of HIV/AIDS infection of pregnant women in the technical tackle, with more profound social significance.

\section{Progress in HIV RNA Laboratory Testing}

Since the early 1990s, quantitative detection of HIV viral load has been recognized as an indicator for evaluating the course of a patient's illness and for evaluating the efficacy of cocktail therapy. High levels of viral RNA can be detected 
in patients with acute infection during the presence of latency by using viral load. Physicians can use those results to determine the course and progression of the patients' disease and to monitor and guide the acceptance of antiviral treatment. Patients can be tested for HIV RNA levels before starting treatment and guided by a series of tests of HIV RNA during treatment. For example, if the level of RNA does not decrease, then we should adjust the treatment or change the treatment plan. If RNA replication is inhibited, continuous treatment should be continued. There are three ways to detect viral load [16] [17], namely, bDNA, RT-PCR and NASBA. BDNA is a technology to detect nucleic acid. It belongs to signal amplification, while RT-PCR and NASBA belong to target amplification. In bDNA detection, the target probe is specifically bound to the pol gene sequence in the HIV genome, which is the most conserved region of all known HIV genes. RT-PCR was used to amplify a $142 \mathrm{BP}$ segment of HIV gag gene by reverse transcription (RT) and amplification (PCR). Since the quantity of QS in each sample is known, the number of HIV RNA copies can be calculated by the formula after amplification and detection by comparing the results of optical density, so as to achieve HIV RNA quantitative purpose. NASBA assay is used to quantify HIV RNA in plasma and serum by releasing and extracting nucleic acid (solid phase extraction), amplifying nucleic acid (NASBA) and detecting nucleic acid (ECL). RT-PCR and NASBA detection belong to the method of PCR, including the steps of extracting RNA, which makes it easy to be contaminated and makes RNA degradation. Compared with RT-PCR and NASBA, bDNA has the characteristic of good stability, linearity and repeatability. Quantitative analysis of HIV RNA in plasma can show the dynamics of virus replication and reflect the concentration of free virus in plasma. It is the result of the interaction of virus proliferation and immune clearance mechanism. Therefore, it has great value in judging the course of disease and judging the clinical therapeutic effect. In this study, real-time fluorescent quantitative PCR was used to detect HIV/AIDS patients, thus the results of which are real, reliable and easy to guide clinical treatment. HIV-1 viral load is an important laboratory testing index [18] [19] in clinical prevention and treatment of AIDS. Effective detection of HIV-1 viral load can evaluate the occurrence, development and progression of AIDS patients, and then guide AIDS patients to determine the timing of treatment, select treatment options, and evaluate the effectiveness of HAART treatment. In addition, clinical symptoms of AIDS patients and other experimental indicators can be combined for diagnosing early opportunistic infection. Furthermore, the detection of plasma HIV-1 viral load can also be used in the early diagnosis of HIV infection in infants and in the detection of blood donors window period samples.

\section{Progress in Counting of HIV/AIDS T Lymphocyte Subsets}

The determination of $\mathrm{T}$ lymphocyte subsets is an important index for the detection of cellular immune function, and is of great significance for the auxiliary diagnosis of some diseases, such as autoimmune diseases, immunodeficiency 
diseases, malignant tumors, hematological diseases, allergic diseases and so on. The HIV virus is a retrovirus, so genetic information exists in two identical RNA single strand templates. The virus can bind to human CD4 receptor cells, especially CD4 T helper lymphocytes. It can also bind to galactose ceramide on the surface of nerve cells. Reverse transcriptase can reverse-transcribe viral RNA into DNA, which then integrates with human genes. The virus DNA sequence is carried by infected cells and their daughter cells for life. HIV can selectively invade lymphocytes with CD4 receptor after entering the body, mainly CD4 T lymphocytes. When the envelope protein gp120 of HIV binds to CD4 receptor on the surface of CD4 T lymphocyte, the membrane of HIV fuses with the cell membrane with the help of gp41, and the virus enters the cell. When the virus enters the cell, it quickly takes off its shell and prepares for further replication. Recent studies have shown that in addition to CD4 receptors, the entry of HIV into cells requires the interaction of proteases on the cell surface with the V3 ring of gp120. HIV-1 is divided into HIV-1 and HIV-2. And HIV-1 infection is characterized by progressive reduction of CD4T lymphocytes [6]. Some studies found that compared with healthy people, activation levels of CD4 T lymphocyte in $\mathrm{HIV}-1$ patients increased by 3-5 times, while CD8 T lymphocyte increased by 5 - 8 times [20] [21]. Although the activation and proliferation of T lymphocyte increased, the total number of CD4 T lymphocytes did not increase, which may be the main compensatory mechanism of CD4T lymphocyte depletion in HIV-1 infected patients [20]. The changes of T lymphocyte subsets not only reflect the degree of immune injury, but also can be used as an objective basis for evaluating the efficacy of drugs and the recovery of immune function in patients with antiviral therapy [22] [23] [24] [25]. The immune function of HIV-infected people is low, mainly manifested in the progressive decrease of CD4 T lymphocyte count with the progression of the disease. The rate of decline depends on the level of HIV replication. The detection of HIV load can reflect the physical condition of AIDS patients. When the CD4 cell count is less than $200 / \mathrm{mm}^{3}$, clinical symptoms gradually appear. Therefore, HIV viral load and T cell subsets have become important indicators for judging the course of HIV infection, predicting clinical progress and evaluating the efficacy of antiretroviral drugs. They play an important role in evaluating the immune status and prognosis of patients with HIV.

\section{Progress in Detection of HIV/AIDS Biochemical Indicators}

Some research suggests that after HIV infection, the body's immune function gradually declines and loses, leading to the occurrence of various immunodeficiency syndrome. In this field, a large number of studies at home and abroad have been done to understand the pathogenesis of HIV infection. However, there has not been much research on the changes of biochemical substances in the blood caused by the destruction of target cells after the HIV virus invades the human body, but it has aroused great attention [26] [27] [28]. In recent 
years, some domestic scholars have made a preliminary analysis of serum biochemical indicators of HIV-infected drug users, and achieved certain results. Studies of SAMUEL K. A. show that HAART can significantly prolong the survival rate and improve the quality of life in HIV-infected patients [29]. However, long-term use of HAART can produce side effects, which may lead to abnormal blood biochemical indicators, and may even endanger life. The study assessed HAART-related blood cell parameters, blood biochemical abnormalities and virological responses in HIV/AIDS infected patients. Blood indices were tested in $200 \mathrm{HIV}$-positive patients before and after HAART according to clinical laboratory conditions. It was found that HAART had a significant effect on viral load, hematology and biochemical parameters. In particular, the effects of blood cells, liver function and renal function are more significant. In order to understand the changes of microbial, biochemical and hematological indicators before and after antiretroviral therapy (ART) in AIDS patients, Obimba, K. C. [30] and other scholars as a parameter for the diagnosis and prognosis of opportunistic infections in AIDS patients. The research team selected HIV-positive patients as the study subjects. The experiment was designed as a single-factor completely randomized design (CRD), with 20 healthy people as the control group and 50 HIV-positive patients as the experimental group. All patients were tested for HIV viral load (VL), CD4 + T lymphocyte count, serum albumi. N (A), serum aspartate aminotransferase (AST), serum total bilirubin, serum total cholesterol (c), serum triglyceride $(\mathrm{T})$, hemoglobin $(\mathrm{Hb})$ test, blood type and genotype test (HIV positive patients), etc. The results showed that the difference between HIV positive group and healthy control group was statistically significant $(\mathrm{P}<0.05)$. These indicators can be used as effective criteria for the diagnosis and prognosis of HIV infection. Therefore, the detection of HIV/AIDS patients with immunological, hematological and biochemical indicators, in the treatment of AIDS and evaluation of therapeutic effect is of great significance.

\section{Summary and Prospect}

To sum up, the relevant literature has not designed the changes of biochemical indicators before and after maternal-fetal blockade. The dynamic analysis of viral load, $\mathrm{T}$ lymphocyte subsets and major biochemical indicators before and after maternal-fetal blockade in pregnant women with HIV/AIDS make it helpful to observe the basic physical fitness and disease development of pregnant women with HIV/AIDS. It can also establish a complete set of laboratory indicators to understand the body status of pregnant women at various stages, so as to minimize the probability of fetal transmission, and has good economic and social benefits.

\section{Acknowledgements}

During the process of this topic research, we got much help from many departments and individuals, and other personnel not involved in this project research. 
All of them offered a great support and help in this research. Now here, all of members in this research show our deepest appreciation to them, and wish them good health and everything goes well.

\section{Funding}

The Guangxi Zhuang Autonomous Region Health Planning Committee self funding research project (NO.: Z2014574), Nanning Guangxi scientific research and technology development project (NO.: 20143154).

\section{Conflicts of Interest}

The authors declare no conflicts of interest regarding the publication of this paper.

\section{References}

[1] UNAIDS (2017) Fact Sheet 2017.

[2] UNAIDS (2017) Ending AIDS: Progress towards the 90-90-90 Targets.

[3] Chinese Center for Disease Control and Prevention, STD/AIDS Prevention and Control Center, STD Control Center. National AIDS Epidemic Report in 2017.

[4] Feyera, A., Megerssa, B., Legesse, D., et al. (2017) Prevention of Mother to Child Transmission of HIV/AIDS: Service Utilization and Associated Factors among Selected Public Health Facilities in Ethiopia. Medical Practice and Reviews, 8, 1-13.

[5] Amare, Z., Biresaw, D. and Hail, S. (2017) Assessment of Factors Affecting the Utilization of Prevention of Mother to Child Transmission (PMTCT) of HIV/AIDS. International Journal of Advanced Research, 5, 304-311. https://doi.org/10.21474/IJAR01/4112

[6] Acharya, R., Acharya, T. and Devkota, R. (2018) Knowledge Regarding Prevention of Mother to Child Transmission of HIV/AIDS among Antenatal Mothers in Nepal. Journal of College of Medical Sciences-Nepal, 14, 44-48. https://doi.org/10.3126/jcmsn.v14i1.18761

[7] Idele, P., Hayashi, C., Porth, T., et al. (2017) Prevention of Mother-to-Child Transmission of HIV and Paediatric HIV Care and Treatment Monitoring: From Measuring Process to Impact and Elimination of Mother-to-Child Transmission of HIV. AIDS and Behavior, 21, S23-S33. https://doi.org/10.1007/s10461-016-1670-9

[8] Tebeu, P.M., Ngo Um Meka, E., Bechem, E., et al. (2017) Evaluation of the Implementation of the WHO's 2010 Guide on Prevention of Mother-to-Child Transmission (PMTCT) of HIV/Aids: Case of Two Hospitals in Yaoundé. Open Journal of Obstetrics and Gynecology, 7, 487-493. https://doi.org/10.4236/ojog.2017.75050

[9] Sherman, G.G., Mazanderani, A.H. and Barron, P. (2017) Toward Elimination of Mother-to-Child Transmission of HIV in South Africa: How Best to Monitor Early Infant Infections within the Prevention of Mother-to-Child Transmission Program. Journal of Global Health, 7, 1-8. https://doi.org/10.7189/jogh.07.010701

[10] Luba, T.R., Feng, Z.C. and Gebremedhin, S.A. (2017) Knowledge about Mother-to-Child Transmission of HIV, Its Prevention and Associated Factors among Ethiopian Women. Journal of Global Health, 7, 1-9.

https://doi.org/10.7189/jogh.07.020414

[11] Sam-Agudu, N.A., Ramadhani, H.O., Isah, C., et al. (2017) The Impact of Struc- 
tured Mentor Mother Programs on 6-Month Postpartum Retention and Viral Suppression among HIV-Positive Women in Rural Nigeria. JAIDS, 75, S173-S181. https://doi.org/10.1097/QAI.0000000000001346

[12] Ambia, J. and Mandala, J. (2016) A Systematic Review of Interventions to Improve Prevention of Mother-to-Child HIV Transmission Service Delivery and Promote Retention. Journal of the International AIDS Society, 19, 20309.

https://doi.org/10.7448/IAS.19.1.20309

[13] Yotebieng, M., Thirumurthy, H., Moracco, K.E., et al. (2016) Conditional Cash Transfers and Uptake of and Retention in Prevention of Mother-to-Child HIV Transmission Care: A Randomised Controlled Trial. The Lancet HIV, 3, e85-e93. https://doi.org/10.1016/S2352-3018(15)00247-7

[14] Myer, L., Dunning, L., Lesosky, M., et al. (2016) Frequency of Viremic Episodes in HIV-Infected Women Initiating Antiretroviral Therapy during Pregnancy: A Cohort Study. Clinical Infectious Diseases, 64, ciw792.

https://doi.org/10.1093/cid/ciw792

[15] Gill, M.M., Hoffman, H.J., Bobrow, E.A., et al. (2016) Detectable Viral Load in Late Pregnancy among Women in the Rwanda Option B+PMTCT Program: Enrollment Results from the Kabeho Study. PLoS ONE, 11, e0168671.

https://doi.org/10.1371/journal.pone.0168671

[16] Eugène, D.M.B., Kroon, N.P., Shattock, A.J., et al. (2017) Acute HIV Infection Detection and Immediate Treatment Estimated to Reduce Transmission by $89 \%$ among Men Who Have Sex with Men in Bangkok. Journal of the International AIDS Society, 20, 21708. https://doi.org/10.7448/IAS.20.1.21708 http://www.jiasociety.org/index.php/jias/article/view/21708

[17] Barminas, K.A., Seljul, R.M.-C., Godwin, I.E., et al. (2017) Detection of HIV Viral Load in Liquid and Dried Plasma Spots among HIV Infected Patients in Jos University Teaching Hospital, Plateau State. Nigeria International Journal of HIVIAIDS Prevention, Education and Behavioural Science, 3, 15-21. https://doi.org/10.11648/j.ijhpebs.20170302.12

[18] Huerga, H., Shiferie, F. and Grebe, E. (2017) A Comparison of Self-Report and Antiretroviral Detection to Inform Estimates of Antiretroviral Therapy Coverage, Viral Load Suppression and HIV Incidence in Kwazulu-Natal, South Africa. BMC Infectious Diseases, 17, 653. https://doi.org/10.1186/s12879-017-2740-y

[19] Zeh, C., Ndiege, K., Inzaule, S., et al. (2017) Evaluation of the Performance of Abbott m2000 and Roche COBAS Ampliprep/COBAS Taqman Assays for HIV-1 Viral Load Determination Using Dried Blood Spots and Dried Plasma Spots in Kenya. PLoS ONE, 12, e0179316. https://doi.org/10.1371/journal.pone.0179316

[20] Isabela, S., Nugroho, A. and Harijanto, P.N. (2018) Association between CD8 T-Cell Subsets and CD4/CD8 Ratio with HS-CRP Level in HIV-Infected Patients on Antiretroviral Therapy. IOP Conference Series. Earth and Environmental Science, 125, Article ID: 012008. https://doi.org/10.1088/1755-1315/125/1/012008

[21] Veel, E., Westera, L., van Gent, R., et al. (2018) Impact of Aging, Cytomegalovirus Infection and Long-Term Treatment for Human Immunodeficiency Virus on CD8+ T-Cell Subsets. Frontiers in Immunology, 9, 572. https://doi.org/10.3389/fimmu.2018.00572

[22] Vuddamalay, Y. and van Meerwijk, J.P. (2017) CD28 and CD28 Low CD81 Regulatory T Cells: Of Mice and Men. Frontiers in Immunology, 8, 31. https://doi.org/10.3389/fimmu.2017.00031

[23] Sebastian, N.T., Zaikos, T.D., Terry, V., et al. (2017) CD4 Is Expressed on a Hetero- 
geneous Subset of Hematopoietic Progenitors, Which Persistently Harbor CXCR4 and CCR5-Tropic HIV Proviral Genomes in Vivo. PLoS Pathogens, 13, e1006509. https://doi.org/10.1371/journal.ppat.1006509

[24] Weinberg, A., Lindsey, J., Bosch, R., et al. (2018) B and T Cell Phenotypic Profiles of African HIV-Infected and HIV-Exposed Uninfected Infants: Associations with Antibody Responses to the Pentavalent Rotavirus Vaccine. Frontiers in Immunology, 8, 2002. https://doi.org/10.3389/fimmu.2017.02002

[25] Mayondi, G.K., Wirth, K., Morroni, C., et al. (2016) Unintended Pregnancy, Contraceptive Use, and Childbearing Desires among HIV-Infected and HIV-Uninfected Women in Botswana: Across-Sectional Study. BMC Public Health, 16, 44. https://doi.org/10.1186/s12889-015-2498-3

[26] Guiateu, T.I.M., Djuidje, N.M., Ambassa, A.C., et al. (2017) Importance of Biochemical Exploration of the Liver in the Control of Disease Progression in People Living with HIV/AIDS and Coinfected by HIV and Hepatitis C Virus in Cameroon. Journal of the Cameroon Academy of Sciences, 13, 81-88.

[27] Yang, J., Fang, Y.H. and Xie, Z.H. (2016) Analysis of the Characteristic of Electrocardiograms with Abnormal Biochemical Indexes of Aids Patients. Medical Recapitulate.

[28] UNAIDS (2016) “Fact Sheet”.org. http://www.unaids.org/en/resources/fact-sheet

[29] Samuel, K.A. (2016) Determination of Haematological and Biochemical Abnormalities in HIV/AIDS Infected Patients Receiving Highly Active Antiretroviral Therapy at the Effiankwanta Regional Hospital in the Western Region. Clinical Microbiology, College of Health Sciences, Kwame Nkrumah University of Science and Technology in Partial Fulfilment of the Requirements, Degree of Master of Science.

[30] Obimba, K.C., Alisi, C.S., Ozougwu, J.C., et al. (2016) Microbial, Biochemical and Hematological Indices of Antiretroviral (ART) Treatment Naïve Human Immunodeficiency Virus (HIV) Seropositive Patients. Int S. J, 6, 345-355.

\section{List of Abbreviations}

HIV: Human immunodeficiency virus

AIDS: Acquired immunodeficiency syndrome

RNA: Ribonucleic acid

DNA: Deoxyribonucleic acid

RT: reverse transcription

PCR: Polymerase chain reaction

NASBA: Nucleic Acid Sequence Based Amplification

CRD: completely randomized design

ART: antiretroviral therapy 